\title{
Advantages of implantation of acellular porcine-derived mesh in the treatment of human rectocele - Case report
}

\author{
Tomasz Kościński', Sebastian Szubert ${ }^{2}$, Stefan Sajdak ${ }^{2}$ \\ ${ }^{1}$ Department of General, Endocrine and Gastroenterological Oncology Surgery, Poznan University of Medical Sciences, \\ Poznan, Poland \\ 2 Division of Gynecological Surgery, Poznan University of Medical Sciences, Poznan, Poland \\ Kościński T, Szubert S, Sajdak S. Advantages of implantation of acellular porcine-derived mesh in the treatment of human rectocele - Case \\ report. Ann Agric Environ Med. 2016; 23(4): 692-695. doi: 10.5604/12321966.1226868
}

\begin{abstract}
Introduction. A rectocele is a hernation of the rectum into the vaginal lumen developing as a consequence of weakness of the rectovaginal septum. It affects about $18 \%$ of women after childbearing age. Symptoms associated with a rectocele include constipation, vaginal fullness or heaviness, feeling of a bulging mass within vagina, incomplete stool evacuation and dyspareunia. Current methods of surgical treatment of a rectocele often require implantation of a mesh graft. In most of cases, synthetic and non-absorbable meshes are used. Although implantation of a synthetic and non-absorbable mesh is effective in the treatment of rectocele, a high rate of mesh erosion has been reported.

Case report. This study presents a surgical technique and case report for the treatment of a rectocele in a 46-year-old women by implantation of a porcine-derived absorbable collagen mesh (Pelvicol ${ }^{\circledR}$ ) by transvaginal approach, with six year follow-up. A review of the literature concerning implantation of Pelvicol ${ }^{\circledR}$ for the treatment of rectocele was also undertaken. Conclusions. The clinical experience and review of the literature by the authors suggest that a porcine-derived acellular mesh is non-cytotoxic, pyrogenic or allergenic, and the application of a biomesh in the management of rectocele is effective and safe, and the risk of mesh erosion is very low.
\end{abstract}

\section{Key words}

rectocele, surgical mesh, pelvic organ prolapse, swine

\section{INTRODUCTION}

A rectocele is a herniation of the rectum through the rectovaginal septum into the vaginal lumen. It develops as a consequence of weakness and thinning of the anterior rectal wall and posterior vaginal wall. It affects about $18 \%$ of women after childbearing age, although the majority of cases are asymptomatic and the incidence may be higher [1]. Rectocele correction is a common gynecological procedure performed during about $40-69 \%$ of operations for pelvic organ prolapse (POP). Among the known risk factors the most important are vaginal delivery, chronic constipation, chronic cough and obesity $[2,3]$.

A rectal wall protruding through a rectovaginal septum creates a kind of diverticulum impeding stool passage, leading to constipation, vaginal fullness or heaviness, feeling of a bulging mass within the vagina, incomplete stool evacuation and discomfort with intercourse [4]. Patients with a rectocele usually complain of constipation characterized by vaginal fullness and an inability to empty the rectum during defecation. Sometimes, digital pressure exerted on the posterior vaginal wall is necessary for defecation [5].

The choice of treatment depends on the severity of symptoms and degree of herniation. Non-surgical therapy of a rectocele includes behavioural management, predominantly avoiding constipation, and the use of mechanical devices. Non-surgical treatment is usually considered in women with a mild to moderate rectocele, those who desire

Address for correspondence: Sebastian Szubert, Division of Gynecological Surgery Poznan University of Medical Sciences, Jablonkowska 26, 61-435 Poznan, Poland E-mail: szuberts@o2.pl

Received: 05 February 2013; accepted 24 September 2014 preservation of childbearing, or when surgical management is contraindicated or not desired by the patient $[6,7]$.

The decision about surgical treatment must be taken very judiciously. The methods of surgical approach for management of a rectocele can be divided into: 1) restorative methods, which the use endogenous support structure, and 2) compensatory methods, replacing pelvic floor defects by graft materials. Graft materials have been used to improve the success of posterior compartment repairs. They are especially desired in the case of large defects or when the primary procedure failed. The idea behind the use of biomaterial grafts is to support weak endogenous tissue.

The main aim of this article is the introduction of new surgical methods for the treatment of rectocele with the use of a porcine-derived acellular mesh.

\section{CASE REPORT}

Surgical technique. 46 year-old-woman was admitted to Department of Gynecological Surgery at the University of Medical Sciences in Poznan, Poland, due to a large rectocele. On admission, the patient complained about constipation, difficulty in emptying the bowel, and discomfort with intercourse. She gave a history of three vaginal deliveries of infants with a birth weight above $3,800 \mathrm{~g}$. The diagnosis of a large rectocele was confirmed after physical examination. The decision of rectocele correction with implantation of Pelvicol ${ }^{\circledR}$ mesh was established.

The technique consists of tension-free coverage of the rectovaginal septum defect, being the portal of entry of the a rectocele, using a Pelvicol ${ }^{\circledR}$ mesh by transvaginal approach. 
The day before surgery, the colon was cleaned mechanically using laxative. Surgery was performed under antibiotic coverage with intravenous cephalospirins and metronidazol administered. The first dose was given at the induction of an aesthesia and continued for 3 days. The patient was placed in the lithotomy position. An arcuate incision was made in the vaginal vestibule and another, perpendicular incision along the midline of posterior vaginal wall, enabling a wide exposure of the rectovaginal space. The large herniation with a hernia ring about $5 \mathrm{~cm}$ in diameter was disclosed. The lateral rims of the levatores ani were moved laterally but it was not possible to merge them together.

A porcine-derived acellular mesh measuring $2 \times 7 \mathrm{~cm}$ and $1 \mathrm{~mm}$ thick was sutured to the lateral rims of the levatores ani muscles, using interrupted absorbable sutures 2-0.
The inferior part of the mesh was attached to the exposed structures of the perineal body. The surgical field was rinsed several times with betaisodone solution, or another disinfectant, and hydrogen peroxide. Redundant vaginal mucosa was excised. The perpendicular incision line was closed using a running absorbable suture (2-0). Incision in the vaginal atrium was closed using interrupted sutures. The surgical technique is summarized in Figure 1.

Six weeks after surgery, functional rectovaginal septum was restored and the patient's complaints were relieved. Currently, after 6 years of follow-up, the effect is stable and the patient free of complaints. From that time, the authors' surgical has performed about 30 operations of rectocele correction with implantation of Pelvicol ${ }^{\circledR}$, with encouraging results.
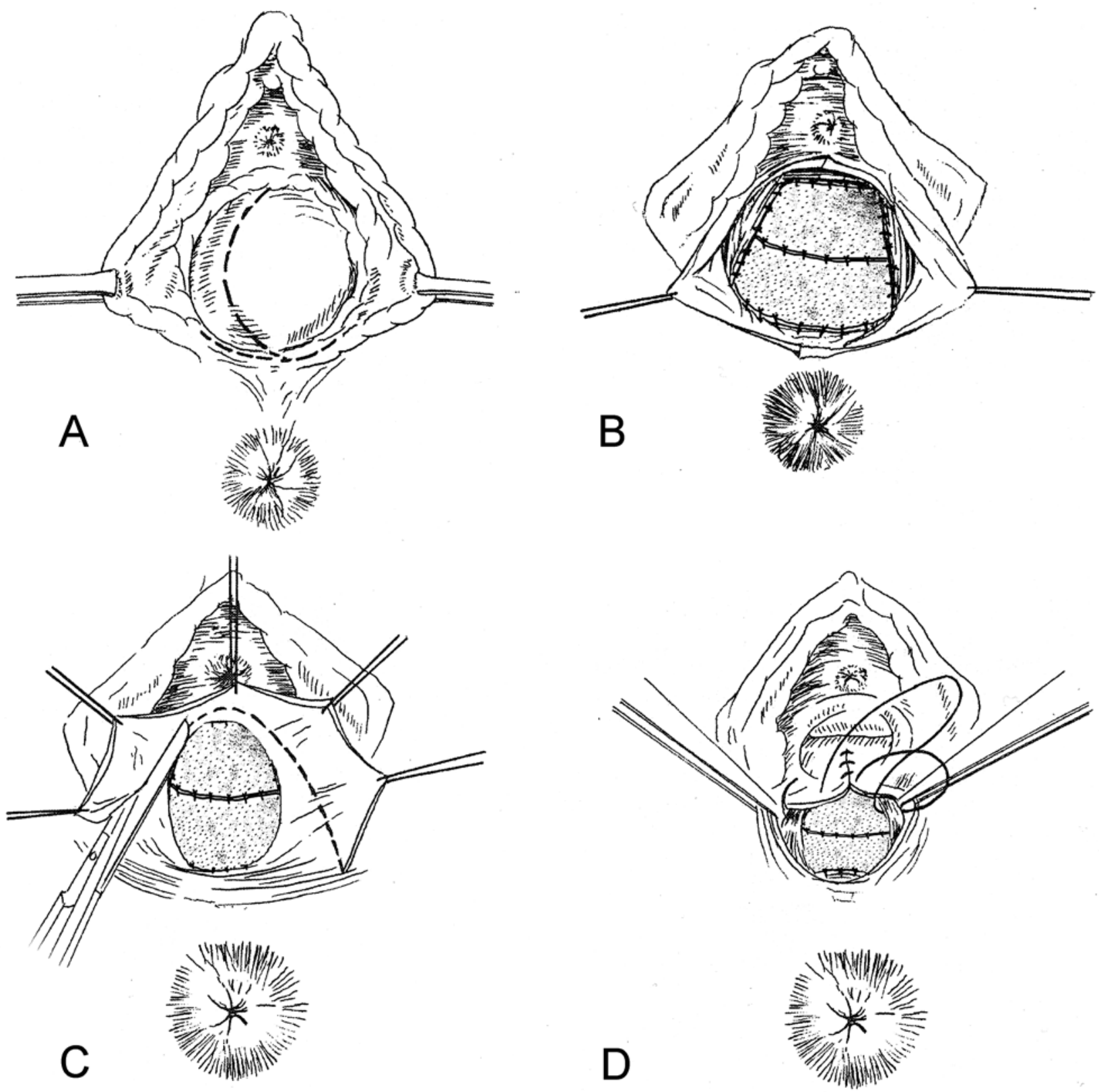

Figure 1. Surgical technique.

A) Surgical approach: incision in vaginal antrum and opening of its posterior wall; B) porcine-derived acellular collagen mesh (Pelvicol') is sutured to lateral rims of levator ani muscles using interrupted absorbable sutures; $\mathrm{C}$ ) excision of redundant vaginal mucosa; $\mathrm{D}$ ) technique of repair of posterior vaginal wall. 


\section{DISCUSSION}

There are various types of meshes used for the treatment of a rectocele, including autologous materials, cadaveric dermis and synthetic materials, e.g. polyglactin, polypropylene, polyester and polyvinyl chloride mesh. According to Cundiff and Fenner, the ideal material for a posterior fascial replacement should have a very low rejection rate, be inexpensive, should decrease the rate of recurrence and cause no harm with respect to bowel and sexual function [8].

Recently, the Pelvicol ${ }^{\oplus}$ mesh, composed of acellular crosslinked porcine dermal collagen, has been introduced for the management of rectocoele [9]. The material consists of collagen type I and elastin fibres obtained from porcine dermis. During the manufacturing process the Pelvicol ${ }^{\oplus}$ mesh undergoes cell removal to reduce immunological response against porcine antigens. The porcine collagen also undergoes cross-linking using hexamethylene-di-isocyanate (HMDI) which results in increased resistance to degradation and reduction of tissue antigenicity. The cross-linked step and agent used in this process are extremely significant for the biological function of Pelvicol ${ }^{\oplus}$. The advantages of Pelvicol ${ }^{\oplus}$ surgical implant over materials which were not crosslinked are demonstrated shown in the study by Gaertner et al. [10]. The presence of HMDI in the Pelvicol ${ }^{\varpi}$ implant causes higher durability and greater tensile strength. It was also demonstrated that the Pelvicol ${ }^{\circledR}$ surgical implant enables cellular infiltration and neovascularisation. When compared with synthethic prolene, Pelvicol ${ }^{\circledast}$ induced milder inflammatory response, less adhesion formation and more orderly collagen deposition, as shown in a rat model [11]. Moreover, the cross-linked materials showed greater resistance to collagenase digestion. The HDMI crosslinked acellular porcine mesh was associated with the best clinical outcomes in contaminated and infected fields, which is especially important in rectal surgery [12]. All of these

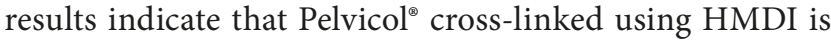
an appropriate material for biological implant.

Data about the use of biological mesh in the management of rectocele, however, is limited. There are only small studies focused on the application of porcine collagen mesh in the treatment of rectocele. Milito et al. [9] operated on 10 women suffering from symptomatic rectocele with the use of porcine collagen implant. During follow-up, ranging from 2-20 months, all patients demonstrated good anatomical results; there were no serious intra- and postoperative complications and the patients reported neither dispareunia nor complaints related to bowel function.

In the study by Altman et al. [13], 17 patients underwent rectocele correction with the use of Pelvicol ${ }^{\varpi}$. The authors compared histological changes 6 months after the operation and compared the results with patients undergoing traditional posterior colporraphy. The histological analysis showed no differences in fibroblast count, connective tissue density, macrophage count, inflammatory cell count, total cell count and inflammatory grading. At the short time evaluation. The only significant difference was higher body temperature on the first day after the operation. The study showed no differences in post-operative complications and duration of hospital stay between the 2 studied groups. In a subsequent study, Altman et al. [14] reported a significant decrease in rectal emptying difficulties, the need for digital support at defecation and defection frequency 6 months after rectocele repair with Pelvicol $^{\circledR}$ implantation. After 12 months of follow-up, symptoms improvement remained, although less significant. In their next report, Altman et al. showed that at a 3 year follow-up, Pelvicol ${ }^{\circledR}$ implantation was associated with significant reduction of rectal emptying difficulties, sense of incomplete evacuation, need for manually assisted defecation, and symptoms of pelvic heaviness [15]. Unfortunately, the failure rate was quite high. At the third year of follow-up, the anatomical recurrence of rectocele was found in clinical examination of $41 \%$ of the treated women, and a decrease in rectal emptying difficulties was reported by less than $50 \%$ of the patients. On the other hand, the procedure was safe, because there were no graft-related complications during the 3 years following surgery [15].

In the study by Taylor et al., 71 patients underwent Pelvicol ${ }^{\oplus}$ implantation for rectocele repair and mesh erosion was found in $7 \%$ of cases. However, the authors did not report the results of their procedure [16]. In the open randomized study by Dahlgren et al. [17], 35 patients had colporrhaphy performed with the use of $\mathrm{Pelvicol}^{\circledR}$ mesh reinforcement, while 26 patients underwent conventional colporrhaphy due to recurrent rectocele. After 3 year follow-up, the results of the treatment did not differ significantly. The failure rates were $23 \%$ and $44 \%$ in the Pelvicol group and conventional colporrhaphy group, respectively. The study showed similar relief of symptoms and complication rate in comparing the use of Pelvicol ${ }^{\Phi}$ with the traditional technique. However, the authors combined the results of anterior and posterior vaginal wall prolapse repair and these results may therefore be inaccurate [17].

Abed et al., combined the meta-analysis showing no differences in mesh erosion in comparing biological and synthetic mesh implantation for the treatment of POP [18]. However, the meta-analysis encompassed all types of POP, including cysto- and rectocoele, vaginal apex prolapsed, etc. The results showed that erosion of both synthetic and biological-derived mesh occured in about $10 \%$ of the operated women [18].

Currently, there is lack of high quality studies comparing rectocele correction with the use of graft augmentation with standard posterior repair without graft implantation. Similarly, there are no prospective randomized trials comparing the use of porcine collagen mesh with synthetic meshes in the treatment of rectocele. In the case of anterior prolapsed repair, Cochrane Collaboration meta-analysis of randomized and quasi-randomized controlled trials showed that the porcine dermis mesh repair was associated with lower failure rate when compared with standard anterior repair [19]. However, in the opinion of the authors of the presented study, the results from anterior vaginal prolapse repair cannot be translated into rectocele treatment.

Recently, Sung et al., [20] published the results of an important study focused on the treatment of rectocele. The authors compared the effect of porcine mesh implantation with the classical repair with native tissue in 137 women suffering from rectocele. After 12 months of follow-up, there were no differences in anatomic failure, occurrence of vaginal bulge and defecatory problems. There were no graft erosions in the study group. However, it should be noted that the material used by Sung et al. [20] was not Pelvicol ${ }^{\oplus}$, it was not cross-linked, and was obtained from the mucosa of porcine small intestine. Moreover, the follow-up of 12 months is considered by the authors of the current study to be too short 
for evaluation of effectiveness of the surgical method for rectocele correction. On the other hand, the study by Sung et al. did show that prepared porcine tissue is safe and can be implemented into the human body.

Every pelvic reconstructive surgeon should be aware of the United States Food and Drug Administration (FDA) statement about the complications associated with transvaginal placement of surgical mesh for pelvic organ prolapsed [21]. In the statement, the FDA warns about the high rate of meshrelated complication in POP surgery and similar effectiveness to traditional non-mesh repair. Although this warning refers predominantly to non-absorbable (permanent) materials, caution should be taken before the making the decision to use absorbable mesh implantation.

\section{CONCLUSIONS}

Although there is still lack of comprehensive randomized trials evaluating the utility of Pelvicol ${ }^{\circledR}$ in the treatment of rectocele, the clinical experience and data obtained from trials conducted by the authors of the presented study indicate that porcine mesh is non-cytotoxic, pyrogenic or allergenic, and the application of biomesh in the management of rectocele is safe and effective.

\section{REFERENCES}

1. Hendrix SL, Clark A, Nygaard I, Barnabei V, McTiernan A. Pelvic organ prolapse in the Women's Health Initiative: gravity and gravidity. Am J Obstet Gynecol. 2002; 186: 1160-1166.

2. Olsen AL, Smith VJ, Bergstrom JO, Colling JC, Clark AL. Epidemiology of surgically managed pelvic organ prolapsed and urinary incontinence. Obstet Gynecol. 1997; 89: 501-506.

3. Whiteside JL, Weber AM, Meyn LA, Walters MD. Risk factors for prolapse recurrence after vaginal repair. Am J Obstet Gynecol. 2004; 191: 1533-15388.

4. Julian TM. Posterior Compartment Defects. In: Rock JA, Howard WJ. Te Linde's Operative Gynecology, 10th Edition, Lippincott Williams \& Wilkins, 2008.p.893-910.

5. Berman L, Aversa J, Abir F, Longo WE. Management of disorders of the posterior pelvic floor. Yale J Biol Med. 2005 Jul; 78(4): 211-221.

6. Maher C, Baessler K, Glazener CM, Adams EJ, Hagen S. Surgical management of pelvic organ prolapse in women. Cochrane Database Syst Rev. 2004; 4:CD004014.
7. Richter HE, Verner RE., Pelvic Organ Prolapse. In: Berek JS., Berek \& Novak's Gynecology, 14th Edition, Lippincott Williams \& Wilkins, 2007.p.898-934

8. Cundiff GW, Fenner D. Evaluation and treatment of women with rectocele: focus on associated defecatory and sexual dysfunction. Obstet Gynecol. 2004 Dec; 104(6): 1403-1421.

9. Milito G, Cadeddu F, Selvaggio I, Grande M, Farinon AM. Transperineal rectocele repair with porcine dermal collagen implant. A two-year clinical experience. Pelviperineology 2010; 29: 76-78.

10. Gaertner WB, Bonsack ME, Delaney JP. Experimental evaluation of four biologic prostheses for ventral hernia repair. J Gastrointest Surg. 2007 Oct; 11(10): 1275-1285.

11. Zheng F, Lin Y, Verbeken E, Claerhout F, Fastrez M, De Ridder D, et al. Host response after reconstruction of abdominal wall defects with porcine dermal collagen in a rat model. Am J Obstet Gynecol. 2004 Dec; 191(6): 1961-1970.

12. Smart NJ, Bryan N, Hunt JA. A scientific evidence for the efficacy of biologic implants for soft tissue reconstruction. Colorectal Dis. 2012 Dec; 14 Suppl 3: 1-6.

13. Altman D, Mellgren A, Blomgren B, López A, Zetterström J, Nordenstam J, et al. Clinical and histological safety assessment of rectocele repair using collagen mesh. Acta Obstet Gynecol Scand. 2004 Oct; 83(10): 995-1000.

14. Altman D, Zetterström J, López A, Anzén B, Falconer C, Hjern F, et al. Functional and anatomic outcome after transvaginal rectocele repair using collagen mesh: a prospective study. Dis Colon Rectum. 2005 Jun; 48(6): 1233-1241.

15. Altman D, Zetterström J, Mellgren A, Gustafsson C, Anzén B, López A. A three-year prospective assessment of rectocele repair using porcine xenograft. Obstet Gynecol. 2006 Jan; 107(1): 59-65.

16. Taylor GB, Moore RD, Miklos JR, Mattox TF. Posterior repair with perforated porcine dermal graft. Int Braz J Urol. 2008 Jan-Feb; 34(1): 84-8.

17. Dahlgren E, Kjølhede P; RPOP-PELVICOL Study Group. Long-term outcome of porcine skin graft in surgical treatment of recurrent pelvic organ prolapse. An open randomized controlled multicenter study. Acta Obstet Gynecol Scand. 2011 Dec; 90(12): 1393-401.

18. Abed H, Rahn DD, Lowenstein L, Balk EM, Clemons JL, Rogers RG. Incidence and management of graft erosion, wound granulation, and dyspareunia following vaginal prolapse repair with graft materials: a systematic review. Int Urogynecol J. 2011; 22: 789-798.

19. Maher C, Feiner B, Baessler K, Adams EJ, Hagen S, Glazener CM. Surgical management of pelvic organ prolapse in women. Cochrane Database Syst Rev. 2010 Apr 14; (4): CD004014.

20. Sung VW, Radin CR, Raker CA, LaSala CA, Myers DL. Porcine subintestinal submucosal graft augmentation for rectocele repair. Obstet Gyneco. 2012 Jan; 119(1): 125-133.

21. U.S. Food and Drug Administration Web Page [5.03.2014], data issued: 13.07.2011: http://www.fda.gov/MedicalDevices/Safety/ AlertsandNotices/ucm262435.htm 